\title{
A survey of copyright advice and guidance in UK higher education libraries
}

\author{
Charles Oppenheim and Ilona Woodward
}

\section{Authors}

Charles Oppenheim is Professor of Information Science in the Department of Information Science at Loughborough University. At the time of writing this article, Ilona Woodward was an undergraduate student in the Department. E-mail: C.Oppenheim@lboro.ac.uk

\begin{abstract}
The results of a questionnaire sent out to members of the lis-copyseek discussion group in Summer, 2003 to assess who currently provides copyright advice in UK higher Education libraries and what concerns these people have. There is a clear feeling that not all the answers given are correct, even though many queries are rated as quite easy. Queries arrive from a variety of sources. There is a need for continued short courses to keep copyright advisors up to date, but lis-copyseek itself is considered by far the most helpful source of information.
\end{abstract}

\section{Acknowledgements}

We wish to thank Laurence Bebbington (another regular contributor of answers to liscopyseek queries) for his helpful advice on the preparation and analysis of the questionnaires. We also wish to thank all the respondents who kindly filled out the questionnaires.

\section{Introduction}

Recent changes in UK copyright law, especially the Directive on copyright and related rights that was passed into UK law at the end of 2003 in the form of a Statutory Instrument, have made the task of providing accurate and reliable advice on copyright matters more difficult than ever for those who work in UK Higher Education libraries. Librarians are in a particularly difficult situation, since they are the natural first port of call for staff and students puzzled by copyright, yet they must be careful not to provide advice that leads a user to infringe copyright, as then the librarian may find him or her-self accused of authorising the infringement in question. This need to be cautious in giving advice (the old joke that the best advice a librarian can give to a patron is "whatever it is you want to do, don't do it" is not that far from reality) clashes with the librarian's ethos of being as helpful as possible to patrons.

To help librarians, for many years there has been an online discussion forum, liscopyseek. This forum, currently run as one of the JISCMAIL discussion groups, is open to all librarians who have to deal with copyright matters. Those who sell electronic or hard copy information, licensing agencies and copyright owners are not permitted to join. The list is un-moderated and its membership largely consists of those working in higher education, although there are some members from government departments and other public sector bodies. Lis-copyseek is a fairly 
typical discussion group in that it has a large number of members who simply "lurk", a reasonable number of people who pose queries and a small number of people, including one of the authors of this article $(\mathrm{CO})$ who regularly respond to the queries.

Because of the increasing concern felt by some librarians regarding the emerging copyright environment, in the late summer of 2003 we prepared a questionnaire and posted it to the lis-copyseek list, inviting members to respond to it. The questionnaire is reproduced in the Appendix. It was sent as an e-mail attachment. It sought to identify what sorts of individuals were members of lis-copyseek, their gender, qualifications and job titles, and then explored how they dealt with copyright inquiries, how they kept themselves up to date and how difficult they found the current copyright environment. At the time the questionnaires were completed, the Statutory Instrument changing UK copyright law had not been passed, but there had been a lot of discussion about early drafts on lis-copyseek.

The vast majority of the completed questionnaires were returned within a week of its posting on the list. Most returns were in the form of a completed attachment, though a few were returned by post. By definition, the respondents were self-selecting; firstly, only members of lis-copyseek were approached with the questionnaire; secondly, only those who felt sufficiently enthusiastic replied to it. The results we describe below must therefore be considered as indicative of the issues that face UK librarians in higher education regarding copyright.

\section{Results}

We received 47 responses; 28 of the respondents were female and 19 were male. 20 respondents had a BA (the subjects were not always specified), 16 had a postgraduate DipLib, one had a Diploma in Information Science, 17 had an MA (again, the subject was not always specified) and four had an MSc (again, subject not always specified), and two had a PhD. 15 had MCLIP after their names and three had FCLIP.

The majority of respondents were in the 41-60-age range. Three of the respondents were aged $20-30 ; 12$ were $31-40 ; 11$ were 41 to $50 ; 17$ were 51 to 60 ; and one was aged more than 60 . A small number refused to specify their age.

Respondents' job titles varied widely, with only the following titles occurring more than once: assistant librarian (four times); copyright officer, acting librarian, learning and information systems manager and senior information officer (three times each); and resources co-ordinator, audiovisual librarians and director of information services (twice each). The vast majority worked in the library (sometimes in special collections), but a small number worked in corporate services, information systems or outreach departments. On average, they had worked in a copyright advisory role for 6.9 years; the longest was 24 years and the shortest one year.

Thirty-eight of the respondents worked in higher education; three worked in further education and one in the not for profit sector; one worked in a national library. The estimated number of staff, students and other patrons they potentially had to deal with ranged from 19 claiming they dealt with up to 5,000 to three who claimed to have to deal with potentially more than 30,000 patrons. 
The respondents were then asked to rate the difficulty of inquiries of the "average" query they received. Rather simplistically, they were asked to classify their response into "very difficult", "quite difficult", "fairly easy" and very easy". Naturally, different queries have different levels of difficulty, but all but one of the respondents stated the average query was either fairly easy or quite difficult. A slightly different picture emerged about their confidence about the answers they gave. Five were very confident, 31 were quite confident, and ten were not very confident. No one admitted to having zero confidence in his or her responses!

Precisely half of those who responded said they had external legal advice they could turn to if need be, and half said they did not. The external advisors were primarily internal legal staff (12), external solicitors (six), colleagues (three) and the University Secretary (two). One respondent each mentioned a partner in a law firm, the JISC Legal Information Service, textbooks, the treasury Solicitor and the Head of Secretariat as external sources.

It is clear from the responses that library staff are in the front line of copyright advice, not just for their patrons but also for non-patrons. Thirty-two of the respondents gave advice throughout their organisation, whilst 13 gave it for the library service only. The most frequently mentioned type of person needing advice, though, were academic staff (45 responses), students (41 respondents) and support units (36 respondents). Two provided advice to other LIS professionals.

All the ways suggested in question 12 for use when answering a query were heavily employed. 26 respondents gave training sessions and a further 13 used workshops for training purposes. Other training methods used were, in decreasing order of frequency, PowerPoint slides, case studies, giving external talks, new staff induction, VLE, tailored in-house session and responding to faculty Board Minutes.

Respondents were asked to rate their agreement with two statements; the first, "I need more internal training", produced a fairly evenly split response with 11 agreeing, 18 disagreeing, but 14 saying there was no appropriate internal training available. The second statement, "I need external training" had nine strongly agreeing, 26 agreeing, eight disagreeing and two strongly disagreeing. It is clear, then, that lis-copyseek members feel the need to have more training in the copyright arena.

The respondents were then asked to rate the quality of support provided by professional associations and other bodies in this field. With $2=$ doing enough and 3 $=$ not doing enough, the average scores were CILIP 2.0, the Patent Office 2.3, CBI 2.9, Universities UK 2.7, JISC 2.0 and SCONUL 2.4. Of the other bodies mentioned, only the Law Society came in for criticism for what it was doing.

Turning to workload, on average respondents only devoted $4.8 \%$ of their time to copyright matters, with an average of about six queries per week. Thus, copyright constitutes only a small proportion of their professional duties.

All the licensing schemes listed were widely used by respondents. The respondents mentioned few other schemes. The main CLA licensing scheme, as with most of those listed, was overwhelmingly considered reasonable value for money; the CLA digitisation scheme produced a split response on value for money, whilst the 
Newspaper Licensing Agency's scheme was considered either reasonable or poor value for money. The only licensing scheme clearly considered to be good value for money was the educational recording Agency's scheme. Turing to the helpfulness of the various reproduction Rights Organisations, all but one of the agencies were generally regarded as being helpful. The one exception was DACS, where the majority felt it was not a helpful organisation.

Here were mixed views on what were the key issues for the future. E-copyright issues generally, scanning and digitisation and e-journal licences were considered the most important, whilst training, copyright enforcement and organisational policies were given the lowest priority.

The key sources for keeping up to date were (perhaps unsurprisingly considering the provenance of the questionnaire) lis-copyseek itself (this received 31 mentions, more than three times the next most frequently mentioned source), CILIP Update, the Patent Office website and the CLA Website. Workshops and seminars, the SCONUL Website and Paul Pedley's Information Law Newsletter were also highly rated.

\section{Conclusions}

Overall, a picture emerges of somewhat harassed library staff who can only devote a small part of their time to copyright queries, yet they receive multiple queries from a variety of sources, and some of these queries they find difficult to handle and are not totally confident about. They feel the need for external courses to keep them updated in particular. More optimistically, they clearly feel that the various discussion groups and newsletters keep them in touch with problems and queries.

The primary implication of this small-scale study is the need for continued self-help in the area of copyright in higher education, and that there is a clear market niche for continued short courses in the field. We are aware of several bodies, including liscopyseek itself, UKOLUG, the Copyright Circle and Aslib who run such courses. With the continued changes in the law promised by the European Commission and new staff becoming involved in copyright in libraries over time, it is likely that such courses will continue to thrive. 


\section{Appendix: LIS-COPYSEEK QUESTIONNAIRE}

\section{A. ABOUT YOU AND YOUR ROLE}

Please answer the following questions about yourself:

1. Sex: Male / Female Qualifications:

Age: $\quad 20-30 \quad 31-40 \quad 41-50$

2. Job Titles:

3. Department:

$51-60$

$60+$ advisory role:

4. Length of time in copyright
5. In which LIS sector do you work?
Education
Corporate
Not-For-Profit
Higher Education
Further

6. Roughly, what is the total potential number of people (e. staff, students,

registered users) in your organisation that could approach you for advice?
$0-5000$
$5,100-10,000$
$10,100-20,000$
$20,100-30,000$

$30,100+$

7. How would you characterise the degree of difficulty of the average copyright query that you deal with?

Very difficult Quite difficult

Fairly Easy Very easy

8. How would you describe your level of confidence in providing copyright advice and guidance?

Very Confident Quite Confident Not Confident Not Confident At All

9. Do you have any professional legal support or backup in providing advice on copyright (e.g. organisational legal office; external company solicitors etc.)? Yes

- University/Institution Solicitors

No If YES please specify:

- External Solicitors

- Colleagues/Other Staff

- University Secretary

Please give us some understanding of your role etc. by answering these questions (please tick as many options as are relevant):

10. Are you responsible for copyright: Throughout your institution

Only for your LIS:

11. Do you provide advice etc. to: Academic staff Students

Support Units External visitors

Others (please specify):

12. Which of the following do you use in providing advice and guidance?

Answer questions in person

Answer questions by email

Printed "in-house" guides

Other guides (e.g. CLA)

Internet pages

Posters (e.g. at copiers)

Other :

13. Do you provide training/education on copyright issues in any of the following ways?

Training sessions

Standard Powerpoint slides

Departmental Workshops

Case Studies

None

Other (please specify):

14. Please tick one box for each of the following two statements according to how strongly you agree or disagree with each statement:

Statement 1: "I need more internal training from my organisation in order to discharge my copyright responsibilities effectively"
Strongly
Agree
Disagree
Strongly
No internal
Agree
Disagree
training is 
available to me

Statement 2: "I need to attend more external training events, funded by my organisation if necessary, in order to discharge my copyright responsibilities

Strongly

Agree effectively"

Agree

Disagree

Strongly

Disagree

15. Please rank in the boxes below on a scale of 1 to 4 whether or not you feel that the following national bodies are doing enough to support you in your role and in raising awareness of copyright law:

1 = doing enough but could do more

3 = not doing enough

2 = doing enough

more

CILIP

Patent Office

$4=$ should be doing a lot

16. Please identify up to three sectoral bodies for your area of work and then use the same rating scale above to assess how much you feel that they are doing to support you in your copyright role. For example, academic sector respondents could identify and rank UniversitiesUK, JISC and SCONUL, while law firms' information specialists might rank The Law Society and BIALL. Sectoral Body (i.e. name) Rank (i.e. enter 1, 2, 3 or 4)

1. UUK

2. JISC

3. SCONUL

ALSO:

B. WORKLOAD

17. Please estimate:
a. the percentage of your working time spent on copyright (e.g. 25\%)

b. the number of queries you deal with each week (e.g. 10)

\section{LICENSING SCHEMES}

18. What licences does your organisation have (please tick any relevant option)?

CLA NLA ERA DACS OU OS

CLA Digitisation Other (please specify):

19. Please rate each of the licences that you have in terms of "value for money" (in terms of the privileges and features that each licence confers in relation to the fees charged):

\section{Very Good Value Reasonable Value}

CLA

Poor Value

CLA Digitisation

NLA

ERA

DACS

OU

OS

(Ordnance Survey)

Other (please specify below):

BGS Crown Click Use MCPS PRS 
20. Taking into account the totality of your dealings with them please assess each of the licensing societies that you deal with according to their helpfulness by ticking an appropriate box:

CLA Very Helpful Helpful Not Very Helpful No Opinion

NLA

ERA

DACS

OU

OS

Other (please specify below):

\section{KEY ISSUES}

22. What do you think are the key issues facing you by ranking the following areas in order of importance (e.g. if Short Loan copyright issues are the most important issue facing you rank it 1 , if you think education/awareness about

Short Loan copyright is next in importance rank it 2 etc., etc.):

Photocopying issues generally

Licences

E-Copyright generally

E-Journal licences

New laws/Keeping Up-To-Date

Education/Awareness

Training

Organisational IP Policy

Copyright Enforcement

Scanning/Digitisation Issues

Other (please specify):

\section{E. KEEPING UP-TO-DATE}

23. What major sources of information (e.g. LIS-COPYSEEK, journals/magazines, weblogs, internal bulletins) do you use to keep up-to-date with copyright developments?

Source (please specify):

TOP 10

1. LIS-COPYSEEK

2. PATENT OFFICE WEBSITE

3. CLA PAGE

4. CILIP UPDATE

5. WORKSHOPS/SEMINARS

6. JOURNALS

7. SCONUL WEBSITE

8. PAUL PEDLEY'S WEBLOG

9. INTERNET GENERALLY

10. MAILING LISTS

OTHERS 